\title{
How general practitioners manage acute asthma attacks
}

\author{
R G Neville, G Hoskins, B Smith, R A Clark
}

\begin{abstract}
Background - The management of asthma attacks by general practitioners in 1992/93 was compared with $1991 / 92$ in relation to recommended guidelines.

Methods - The findings from a postal survey of 299 UK general practitioners who managed 2332 patients with an asthma attack in 1992/93 were compared with those from 218 practitioners who managed 1805 attacks in 1991/92. Management by a subgroup of practitioners from a special interest group was analysed separately.

Results - In 1992/93 2031 (87\%) of attacks were managed entirely by general practitioners, 251 (11\%) were referred for admission to hospital, and $50(2 \%)$ were managed by an accident and emergency department. There was no change in the pattern of management relative to 1991/92. Compared with recommended guidelines there was underuse of systemic steroids and nebulised bronchodilators. Between $1991 / 92$ and $1992 / 93$ use of systemic steroids in acute attacks increased from $56 \%$ to $71 \%$, nebulised bronchodilators from $31 \%$ to $32 \%$, and an increase in prophylactic medication after an acute attack from $41 \%$ to $49 \%$. Contrary to guidelines, antibiotic use increased from $32 \%$ to $40 \%$ of attacks. Practitioners from a special interest asthma group gave more of their patients systemic steroids and nebulised bronchodilators both in 1991/92 and 1992/93.

Conclusions - Some aspects of the management of asthma attacks by general practitioners has changed in line with guidelines, but there is still a large gap between actual and recommended management.

(Thorax 1997;52:153-156)
\end{abstract}

Keywords: asthma, general practitioner, management, guidelines.

Tayside Centre for General Practice, University of Dundee, Dundee DD2 4AD, UK

R G Neville

G Hoskins

B Smith

R A Clark

Correspondence to:

Dr R G Neville.

Received 7 November 1995

Returned to authors

22 December 1995

Revised version received

28 August 1996

Accepted for publication

2 September 1996
Asthma is a major health care problem. ${ }^{1-4}$ Mortality and morbidity are at unacceptably high levels despite the availability of effective treatments in primary and secondary care. ${ }^{5-9}$ National, regional, and international guidelines ${ }^{10-14}$ have acted as criteria for best attainable management around which audit studies have been attempted. ${ }^{15}$ The 1991/92 audit of asthma attacks in general practice highlighted the gap between recommended and actual management of acute attacks by general practitioners. ${ }^{17}$ Concern was raised at the underuse of systemic steroids and nebulised bronchodilators - the mainstay of acute attack man- agement - in attacks of all degrees of severity. There has been a concerted effort by professional bodies to address the problem of suboptimal asthma management. The publication of revised UK asthma guidelines in 1993 presented the opportunity to repeat a national audit of asthma attacks in general practice and to assess whether general practitioners had instituted changes in the management of acute attacks in line with the guidelines.

This paper compares the findings from the 1992/93 audit of asthma attacks in UK general practice with the 1991/92 audit and assesses whether or not favourable changes in management have occurred.

\section{Methods}

RECRUITMENT

In 1991/92 218 general practitioners supplied details of 1805 patients of all ages who had recently experienced an acute asthma attack. One hundred and three participating practitioners were members of the special interest group General Practitioners in Asthma Group (GPIAG) and the remainder were respondents to a mailing invitation to a random sample of UK practitioners.

To recruit a target of 2000 patients with asthma attacks in 1992/93 it was estimated that at least 200 general practitioners would need to participate. A medical mailing agency was commissioned to invite a random sample of 5000 of the 33000 general practitioners in the UK, stratified by region, to participate in an audit exercise. In addition, those practitioners who participated in 1991/92 were offered the chance to participate in $1992 / 93$.

The 1991/92 study thus comprised a sample of practitioners, approximately half of whom belonged to a special interest group (GPIAG) and half were practitioners motivated to enrol in a national audit. GPIAG membership indicates motivation and interest rather than assessed expertise. The participants in the 1992/93 study, whether GPIAG members or not, represent a UK sample of motivated and interested (but not necessarily expert) general practitioners.

\section{ASTHMA ATTACKS}

Participating practitioners supplied details of all their patients, of all ages, who experienced an asthma attack over a predetermined three month period. For logistical reasons, and to avoid seasonal trends in attacks, the three month period was staggered into four separate blocks. An attack was defined as "an episode 
Table 1 Geographical distribution of general practitioners who participated in the 1992/93 audit

\begin{tabular}{|c|c|c|c|c|c|c|c|}
\hline \multirow[t]{2}{*}{ Region } & \multicolumn{3}{|c|}{ No. of participants $(n=297)$} & \multicolumn{3}{|c|}{ Distribution of participating practices (\%) } & \multirow{2}{*}{$\begin{array}{l}\text { Practice population } \\
\text { distribution of UK } \\
(\%)^{18}\end{array}$} \\
\hline & GPIAG members & Non-members & Total & GPIAG members & Non-members & Total & \\
\hline North East & 4 & 11 & 15 & 1 & 3 & 5 & 5 \\
\hline North West & 6 & 14 & 20 & 2 & 5 & 7 & 10 \\
\hline Midlands & 18 & 40 & 58 & 6 & 13 & 20 & 17 \\
\hline Wessex & 9 & 15 & 24 & 3 & 5 & 8 & 5 \\
\hline Greater London and South East & 13 & 43 & 56 & 4 & 14 & 19 & 22 \\
\hline South West & 5 & 15 & 20 & 1 & 5 & 7 & 7 \\
\hline Thames Valley & - & 3 & 3 & - & 1 & 1 & 4 \\
\hline East Anglia & 2 & 12 & 14 & $<1$ & 4 & 5 & 4 \\
\hline Yorkshire & - & 13 & 13 & - & 4 & 4 & 6 \\
\hline Northern Ireland & 2 & 8 & 10 & $<1$ & 3 & 3 & 4 \\
\hline Wales & 4 & 14 & 18 & 1 & 5 & 6 & 5 \\
\hline Scotland & 13 & 33 & 46 & 4 & 11 & 15 & 11 \\
\hline
\end{tabular}

of respiratory symptoms which prompts an urgent consultation with a doctor, is of sufficient severity to prevent the patient working/ attending school/performing domestic duties/ playing, and results in increased use of antiasthma medication". ${ }^{17}$ In the UK general practitioners have a defined list of patients ${ }^{3}$ so all patients who presented with an asthma attack - whether managed by themselves, a deputy, partner, or a hospital - were included.

The 1992/93 and 1991/92 studies sought the same practice and patient details. Questions about practice resources included whether or not a practice asthma clinic was in operation, employed a trained practice nurse, owned a nebuliser, used an asthma protocol, or operated a register of patients with asthma.

Patient details included age, sex, use of prophylactic therapy, possession of a peak flow meter, use of a self management plan, severity of symptoms on presentation, clinical assessment on presentation (pulse rate, blood pressure, respiratory rate), and use of systemic steroids, nebulised bronchodilators and changes in prophylactic medication.

ANALYSIS OF DATA

Results from participating general practitioners and their patients were collated. The actual management each patient received was com- pared with recommended management according to guidelines. ${ }^{14}$ Practice resourcing of asthma care in 1991/92 was compared with 1992/93. Results from patients managed by GPIAG members were compared with those of non-members. Clinical signs on presentation and treatment administered by practitioners were compared using the $\chi^{2}$ test and presented as odds ratios (OR) with $95 \%$ confidence intervals. Results where confidence intervals do not include one (a rough proxy for $\mathrm{p}<0.05$ ) are shown in bold type in the tables.

\section{Results}

PARTICIPANTS

In the 1992/93 survey 299 general practitioners participated and returned useable information on 2332 patients with an asthma attack in the specified time frame. The recruitment target for participants and patients was thus exceeded. The geographical spread of participants included all regions of the UK (table 1 ). ${ }^{18}$ Practice resourcing of asthma care showed few changes between 1992/93 and 1991/92 (table 2).

\section{PATIENTS}

The male:female ratio was 48:52. There were $659(29 \%)$ in the $0-9$ age group, $336(15 \%)$ in the 10-19 age group, $256(11 \%)$ in the 20-29 age group, $193(9 \%)$ in the $30-39$ age

Table 2 Comparison of 1991/92 and 1992/93 audits of asthma attacks in general practice

\begin{tabular}{|c|c|c|c|}
\hline & $1992 / 93$ & $1991 / 92$ & $\begin{array}{l}\text { Comparison between } \\
1992 / 93 \text { and } 1991 / 92 \\
\text { odds ratio ( } 95 \% \text { CI) }\end{array}$ \\
\hline $\begin{array}{l}\text { No. of participating GPs } \\
\text { No. of reported attacks }\end{array}$ & $\begin{array}{r}299 \\
2332\end{array}$ & $\begin{array}{r}218 \\
1805\end{array}$ & \\
\hline $\begin{array}{l}\text { Place of management } \\
\text { General practice } \\
\text { Admitted to hospital } \\
\text { Accident and emergency }\end{array}$ & $\begin{array}{r}2031(87) \\
251(11) \\
50(2)\end{array}$ & $\begin{array}{r}1546(86) \\
225(12) \\
34(2)\end{array}$ & $\begin{array}{l}1.13(0.94 \text { to } 1.36) \\
0.85(0.70 \text { to } 1.03) \\
1.14(0.72 \text { to } 1.81)\end{array}$ \\
\hline $\begin{array}{l}\text { Practice resources } \\
\text { Practice asthma clinic } \\
\text { Own nebuliser } \\
\text { Register of asthmatics } \\
\text { Practice asthma protocol } \\
\text { Trained practice nurse }\end{array}$ & $\begin{array}{l}221(74) \\
287(96) \\
262(88) \\
205(69) \\
210(70)\end{array}$ & $\begin{array}{l}159(73) \\
204(94) \\
179(82) \\
135(62) \\
167(77)\end{array}$ & $\begin{array}{l}1.08(0.71 \text { to } 1.63) \\
2.19(0.87 \text { to } 5.60) \\
1.68(0.99 \text { to } 2.84) \\
1.43(0.97 \text { to } 2.11) \\
0.75(0.49 \text { to } 1.14)\end{array}$ \\
\hline $\begin{array}{l}\text { Self management } \\
\text { Patients with self management plan before attack } \\
\text { Self management plan followed by patients before attack } \\
\text { Possession of peak flow meter before attack }\end{array}$ & $\begin{array}{l}795(34) \\
590(74) \\
808(35)\end{array}$ & $\begin{array}{l}615(34) \\
406(66) \\
516(29)\end{array}$ & $\begin{array}{l}1.07(0.94 \text { to } 1.23) \\
\mathbf{1 . 6 4}(\mathbf{1 . 2 7} \text { to } 2.12)^{*} \\
1.02(0.89 \text { to } 1.18)\end{array}$ \\
\hline $\begin{array}{l}\text { Symptom severity on presentation } \\
\text { Not breathless } \\
\text { Moderately breathless } \\
\text { Breathless and distressed } \\
\text { Too breathless to talk } \\
\text { Moribund }\end{array}$ & $\begin{array}{r}457(20) \\
1216(52) \\
554(24) \\
64(3) \\
0(-)\end{array}$ & $\begin{aligned} & 248(14) \\
& 900(50) \\
& 535(30) \\
& 68(4) \\
& 2(-)\end{aligned}$ & $\begin{array}{l}1.51(1.27 \text { to } 1.80)^{*} \\
1.07(0.94 \text { to } 1.22) \\
\mathbf{0 . 7 3}(\mathbf{0 . 6 3} \text { to } \mathbf{0 . 8 4})^{*} \\
0.71(0.50 \text { to } 1.02)\end{array}$ \\
\hline
\end{tabular}

Values in parentheses are percentages.

* Confidence intervals do not include one. 
Table 3 Management of acute asthma attacks

\begin{tabular}{|c|c|c|c|c|c|c|c|}
\hline & \multicolumn{3}{|l|}{$1992 / 93$} & \multicolumn{3}{|l|}{$1991 / 92$} & \multirow{2}{*}{$\begin{array}{l}\text { Comparison of totals } \\
\text { from } 1992 / 93 \text { and } 1991 / 92 \\
\text { odds ratio }(95 \% \mathrm{CI})\end{array}$} \\
\hline & GPIAG members & Non-members & Total & GPIAG members & Non-members & Total & \\
\hline No. of participating GPs & 76 & 223 & 299 & 103 & 115 & $218^{*}$ & \\
\hline No. of patients managed by GP & 595 & 1436 & 2031 & 774 & 772 & 1546 & \\
\hline Systemic steroids & $438(74)$ & $997(69)$ & $1435(71)$ & $594(77)$ & $269(35)$ & $863(56)$ & $1.91(1.65 \text { to } 2.19)^{*}$ \\
\hline Nebulised bronchodilators & $207(35)$ & 449 (31) & $656(32)$ & $270(35)$ & $207(27)$ & $477(31)$ & $1.07(0.92$ to 1.24$)$ \\
\hline Increase after attacks & $319(54)$ & $681(47)$ & $1000(49)$ & $359(46)$ & $273(35)$ & $632(41)$ & $1.40(1.22 \text { to } 1.61)^{*}$ \\
\hline Antibiotics & $187(31)$ & $635(44)$ & $822(40)$ & $199(26)$ & $290(38)$ & $489(32)$ & $1.47(1.28$ to 1.69$) *$ \\
\hline
\end{tabular}

Values in parentheses are percentages.

* Confidence intervals do not include one.

group, 178 (8\%) were aged 40-49, 202 (9\%) 50-59 years, 243 (11\%) 60-69 years, and 208 $(9 \%)$ were aged $>70$. The age was unknown in 57 cases.

PLACE OF MANAGEMENT

General practitioners initially saw 2234 (96\%) patient attacks and managed $2031(87 \%)$ themselves; $251(11 \%)$ were admitted to hospital and $50(2 \%)$ were managed and discharged from an accident and emergency department (table 2). This pattern of care was very similar to that seen in 1991/92. Four patients died in the course of their attacks, all of whom had been admitted to hospital but died despite treatment. Their ages were $66,72,74$, and 92 years.

SELF MANAGEMENT

Self management plans were followed by 590 $(74 \%)$ of the 795 patients who were in possession of a plan before their attack compared with $66 \%$ in $1991 / 92$ (odds ratio $1.64,95 \%$ confidence intervals 1.27 to 2.12 ). Peak flow meters had been prescribed to $808(35 \%)$ of patients compared with only $516(29 \%)$ in 1991/92.

RECORDING OF CLINICAL DATA

There was a written record of respiratory rate in $1293(55 \%)$ patients, pulse rate was recorded in $1376(59 \%)$ patients, the presence or absence of cyanosis was noted in $1871(80 \%)$, and a record of peak flow rate in 1595 (68\%). Clinical recording and documentation in the case records of pulse rate and presence or absence of cyanosis was more complete in the 1992/93 study than in 1991/92. Recording and documentation of respiratory rate and peak flow rate were less complete. The best documented measure of severity was a simple grading system based on degree of breathlessness and data for this variable suggested a shift towards earlier presentation and diagnosis of asthma attacks in $1992 / 93$ compared with $1991 / 92$ (table 2).

TREATMENT

Systemic steroids were given to 1435 (71\%) of patients managed exclusively by general practitioners in 1992/93 compared with $56 \%$ in $1991 / 92$ (odds ratio $1.91,95 \%$ CI 1.65 to $2.19)$. Increased use of systemic steroids was apparent in the treatment of attacks of all grades of severity. Nebulised bronchodilators were given to $656(32 \%)$ patients in 1992/93 managed exclusively by general practitioners compared with $31 \%$ in $1991 / 92$ (OR $1.07,95 \%$ CI 0.92 to 1.24$)$.

Medication given after the asthma attacks was increased in line with recommended guidelines in 1000 of the 2031 (49\%) patients in $1992 / 93$ managed exclusively by general practitioners compared with $41 \%$ in $1991 / 92$ (OR $1.40,95 \%$ CI 1.22 to 1.61 ).

Antibiotics were prescribed during the management of 822 of the 2031 attacks $(40 \%)$ in $1992 / 93$ compared with 489 of the 1546 attacks $(32 \%)$ in $1991 / 92$ (OR 1.47, 95\% CI 1.28 to 1.69), although recommended guidelines suggest that antibiotics should not be administered routinely (table 3 ).

GPIAG SPECIAL INTEREST GROUP

Practitioners who belonged to the GPIAG gave systemic steroids and nebulised bronchodilators to more of their patients than nonGPIAG practitioners both in 1991/92 and $1992 / 93$. Further detailed statistical analysis of GPIAG members was unremarkable. The GPIAG practitioners showed relatively little change in their management between 1991/92 and 1992/93 compared with non-members of the group (table 3 ).

\section{Discussion}

The results of this study show that systemic steroids and nebulised bronchodilators, the mainstay of emergency treatment of acute asthma attacks, were underused. Despite the publication and distribution of guidelines there remains a substantial gap between actual and recommended management. On a more encouraging note, general practitioners in 1992/ 93 used more systemic steroids and increased preventative treatment more often than in $1991 / 92$. Contrary to recommended guidelines, antibiotics were used more often in 1992/ 93 than in 1991/92. Whether this reflects a more liberal use of all types of medication or a misunderstanding in the key messages of the guidelines is uncertain.

Most of the acute asthma attacks were managed by general practitioners themselves with only a few being referred or admitted to hospital. Hospital based chest physicians need to consider how best to educate, support, and resource their primary care colleagues who manage most of the acute asthma pre- 
sentations. Guidelines alone may not be enough. Multidisciplinary meetings, local interest groups, and a local expert advice service may be needed to bring general practice management more in line with modern guidelines.

The changes observed between 1991/92 and $1992 / 93$ could be due to changes in general practitioner management, changes in how and when patients presented, changes in practice resourcing of asthma care, or due to a sampling artefact. There is no evidence to suggest a change in practice resourcing. There is some evidence that patients may have presented earlier in the course of attacks and the increased use of self management plans between 1991/ 92 and 1992/93 supports the view that patient education may have altered. Sampling artefact amongst patients is unlikely because both studies involved large numbers of patients of all ages drawn from throughout the UK. Some sampling artefact amongst practices will have occurred because recruitment relied on individual practitioners responding to an invitation. Participants are therefore a self selected group with a common interest and enthusiasm. This interest did not extend to providing optimum management of acute asthma attacks in $1991 / 92$ or $1992 / 93$. Although the mix of practitioners in 1992/93 may differ slightly from $1991 / 92$, and the patients studied may have presented earlier, the major shift in results appears to be due to a change in how general practitioners managed attacks.

It is unreasonable to expect practitioners to have followed recommended guidelines to the letter in all cases. Individual patients have individual management needs. Not all patients who presented and are included in the study had "acute severe asthma" and so it is unrealistic to expect every patient to have received nebulised bronchodilators and systemic steroids. Some patients, especially young children, may respond rapidly to bronchodilators given through a spacer device and more aggressive treatment with a nebuliser or systemic steroids may have been deliberately omitted by practitioners.

Whilst it is likely that the publication and distribution of guidelines may be the reason for the favourable changes seen in management, it is important to consider other possible explanations. In the early 1990 s UK general practices experienced many changes such as the imposition of a contract which included remuneration for asthma clinics, an incentive scheme to promote postgraduate education, and the widespread policy of training practice nurses in the skills of asthma management. The relative contribution of each factor to the changes seen is unknown but the promotion of guidelines is common to all the factors.

Health care professionals who respond to an invitation to participate in a clinical audit are by definition atypical. All studies based on self reporting by clinicians of patient management are subject to bias. The results from practitioners who completed both studies and thus an audit cycle are of particular interest to general practice educationalists and are published in detail elsewhere. A problem that occurs with comparison of results between 1991/92 and $1992 / 93$ is whether to include those practitioners who participated in both studies. The changes which occurred in the management of acute asthma attacks are present whether one includes or excludes this "audit group". We opted to include them.

Results from members of the GPIAG showed that their patients received management more in line with guidelines both in 1991/92 and 1992/93, although there was little change between successive surveys (table 3 ). Whilst GPIAG membership is a marker of enthusiasm rather than assessed competence, it would appear to be associated with concordance with recommended guidelines.

Successive studies have shown a discrepancy between advised and actual practice in the primary care management of acute asthma attacks. This discrepancy is less with practitioners who belong to a special interest group. In practitioners who are not members of a special interest group there have been encouraging changes in management between 1991/92 and 1992/93.

We thank all the doctors who took part for their willingness to participate in critical audit, and all our colleagues from GPIAG, BTS, and the University of Dundee for helpful comments and sensible advice. This paper is dedicated to the memory of Diane Gregory.

The General Practitioners in Asthma Group receives an educational grant from Allen and Hanburys Ltd.

1 Gregg I. Epidemiological aspects. In: Clark TJH, Godfrey S, eds. Asthma. 2nd edn. London: Chapman and Hall, 1983:242-84

2 Pedersen PA, Weeke ER. Asthma in Danish general practice. Allergy 1981;36:175-81.

3 OPCS, RCGP, DHSS. Third national study of morbidity statistics from general practice, 1981/85. Thorax 1990;45: $431-7$.

4 Von Mutius E, Fritzsch C, Weiland S, Roll G, Magnussen $\mathrm{H}$. Prevalence of asthma and allergic disorders among children in United Germany: a descriptive comparison. children in United Germa

5 Alderson $M$. Trends in morbidity and mortality from asthma. London: Office of Population Censuses and Surveys, HMSO, 1987.

6 British Thoracic Association. Death from asthma in two regions of England. BMF 1982;285:1251-5.

7 Anderson HR. Trends and district variations in the hospital care of childhood asthma: results of a regional study 1970-85. Thorax 1990;45:431-7.

8 Burney PG. Strategy for asthma. BMf 1991;303:571-3.

9 Grampian Asthma Study of Integrated Care (GRASSIC). Integrated care for asthma: a clinical, social and economic evaluation. BMf 1994;308:559-64

10 Warner JO, Götz M, Landon L, Levison H, Milner A, Pedersen S, et al. Management of asthma: a consensus statement. Arch Dis Child 1989;64:1085-79.

11 Bucknall CE, Robertson C, Moran F, Stevenson RD. Management of asthma in hospital: a prospective audit. $B M \mathcal{F}$ 1988;296:1637-9.

12 British Thoracic Society, Royal College of Physicians of London, King's Fund Centre, National Asthma Campaign. Guidelines for management of asthma in adults I: Chronic persistent asthma. BMF 1990;301:651-3.

13 British Thoracic Society, Royal College of Physicians of London, King's Fund Centre, National Asthma Campaign. Guidelines for management of asthma in adults II: Acute severe asthma. BMF 1990;301:797-800.

14 British Thoracic Society and others. Guidelines for the management of asthma: a summary. $B M \mathcal{F} 1993 ; 306: 776$ 82.

15 Bell D, Layton AJ, Gabbay J. Use of guidelines based questionnaire to audit hospital care of acute asthma. $B M \mathcal{F}$ 1991;302:1440-3

16 Lim KL, Harrison BDW. Criterion based audit of inpatient asthma care. Thorax 1991;46:316-7.

17 Neville RG, Clark RA, Hoskins G, Smith B for General Practitioners in Asthma Group. National asthma attack Practitioners in Asthma Group. Nation

18 Health and Personal Social Services Statistics for England and Wales. Scottish Health Statistics 1994. London: HMSO, 1994 .

19 Hoskins G, Neville RG, Smith B, Clark RA. Does participation in clinical audit alter patient management? (in press). 